\title{
Assess the Effectiveness of Structured Childbirth Education Program on Preparedness toward Labor for Primigravidae
}

\author{
${ }^{1}$ Geeta Bharadwaj, ${ }^{2}$ Simer Preet Kaur
}

\begin{abstract}
Objectives: To assess the knowledge of the primigravida before the structured childbirth education program, to assess the knowledge of the primigravida after the structured childbirth education program, to evaluate the effectiveness of structured childbirth education program in terms of gain in knowledge scores and to associate the knowledge scores with selected demographic variables.
\end{abstract}

Methods: The quasi-experimental research approach was used for this study with pretest post-test design. The sample size was 60 primigravidae. Non-probability convenient sampling technique was used for the selection of samples. Data collection was accomplished by using structured questionnaire with two sections. First, section dealt with baseline data of primigravidae and second, section dealt with knowledge of primigravidae related to labor process. Structured childbirth education program was prepared on childbirth process including all major topics related to labor and its preparation.

Results: Data were analyzed based on objectives and hypothesis. Data analyzed by using descriptive and inferential statistics. Based on the analysis, interpretations were made. During comparison of pretest and the post-test knowledge scores of the samples researcher found, in pretest, majority of the samples $40(66.66 \%)$ got poor knowledge score, whereas in post-test only two samples got poor knowledge score. In pretest $19(31.66 \%)$ got average score, but in post-test majority, i.e. $36(60 \%)$ got average score. In pretest, only single sample got good knowledge score but in post-test 22 (36.66\%) samples got good knowledge score and the mean of pretest is very less, i.e. 7.05 with standard deviation (SD) 3.561016 as compared to post-test, where mean is 15.2 with SD 3.590729 't' calculated value, i.e. 5.096322 is greater than 't' table value, i.e. 2.238152. This difference was statistically significant at $p<0.01$ level with t-value of 5.096322 .

Conclusion: Based on analysis, following inference was made. There was significant increase in knowledge after structured childbirth education program. Structured childbirth education program is found to be effective to increase primigravidae's

\footnotetext{
${ }^{1}$ Demonstrator, ${ }^{2}$ Lecturer

1,2Department of Obstetrics and Gynecological Nursing, Uttar Pradesh RIMS and R Nursing College, Saifai, Uttar Pradesh India
}

Corresponding Author: Geeta Bharadwaj, Demonstrator Department of Obstetrics and Gynecological Nursing, Uttar Pradesh RIMS and R Nursing College, Saifai, Uttar Pradesh India, Phone: 9627789732, e-mail: gaurav.gyani@gmail.com knowledge related to labor process. The researcher found that there is no association of knowledge score with any of the selected demographic variable.

Keywords: Knowledge, Labor, Primigravidae, Structured childbirth education program.

How to cite this article: Bharadwaj G, Kaur SP. Assess the Effectiveness of Structured Childbirth Education Program on Preparedness toward Labor for Primigravidae. J South Asian Feder Obst Gynae 2015;7(3):106-108.

Source of support: Nil

Conflict of interest: None

Date of received: 14 June 2015

Date of acceptance: 15 August 2015

Date of publication: December 2015

\section{INTRODUCTION}

A woman's experience of birth is vitally important, and her birth memories endure. Four factors are particularly important in determining a woman's childbirth experience: personal expectations, the amount of support she receives, the quality of the caregiver-patient relationship, and her involvement in decision-making. ${ }^{1}$ Women are always prepared for the birth of their babies. Mothers from all cultures traditionally passed their knowledge about labor and birth to their daughters. These cultural and family rituals guided women through pregnancy, labor, birth and the early days of mothering. Much of women's wisdom about birth was lost, when birth moved from home to hospital. Mothers, sisters, and other women knowledgeable about birth no longer attended the woman. Birth became a medical event and cultural and family rituals took a back seat, eventually all but disappearing. The development of structured educational programs in preparation for childbirth came about as the traditional methods of information sharing declined. Nurses and physical therapists, who knew a great deal about the mechanics and medical management of pregnancy, labor and birth, began to educate women about childbirth, largely outside of the healthcare system. Eventually, these professionals became formally trained as childbirth educators. ${ }^{2,3}$ 
Assess the Effectiveness of Structured Childbirth Education Program

Table 1: Comparison of pretest knowledge score and post-test knowledge score of the samples $(\mathrm{N}=60)$

\begin{tabular}{lllll}
\hline Knowledge score & Pretest frequency & Percentage & Post-test frequency & Percentage \\
\hline Poor & 40 & 66.66 & 2 & 3.33 \\
Average & 19 & 31.66 & 36 & 60 \\
Good & 1 & 1.66 & 22 & 36.66 \\
\hline
\end{tabular}

Table 2: Mean and SD of pretest and post-test knowledge scores of samples

\begin{tabular}{llllll}
\hline & Mean & $S D$ & 't' calculated & 't' table & $p$-value \\
\hline Pretest & 7.05 & 3.561016 & 5.096322 & 2.238152 & 0.000324 \\
Post-test & 15.2 & 3.590729 & & & \\
\hline
\end{tabular}

Childbirth education has probably existed in some form since our earliest ancestors learned to speak and hand information from one-to-another. The first, structured childbirth education programs came from England to the United States via the Maternity Center Association of New York, after the 1932 publication of Grantley Dick-Read's landmark book Childbirth without Fear. Throughout the 1940s, the 'Read Method,' which advocated reducing pain in childbirth by using knowledge to diminish fear, which in turn, decreased pain, was the basis for prepared childbirth classes. ${ }^{1}$

\section{METHODS}

The quantitative quasi-experimental research approach was used for this study with pretest post-test design. The sample size was 60 primigravidae. Nonprobability convenient sampling technique was used for selection of samples. Data collection was accomplished by using structured questionnaire consisted of two sections, first section dealt with baseline data of primigravidae and second section dealt with knowledge of primigravidae related to labor process. Structured childbirth education program was prepared on childbirth process including all major topics related to labor and its preparation. The final data collection was done from primigravidae by pretest post-test method, structured childbirth education program was administered after pretest and, after 1 week post-test was conducted. Data gathered was analyzed by using descriptive and inferential statistics. Based on the analysis, interpretations were made.

\section{RESULTS}

The significant findings of the study were 51 (85\%) primigravidae were in the age group of 19 to 25 years. In terms of education, 30 (50\%) had secondary education. With regards to family type 46 (76.6\%) were living in joint family. In terms of months of gestation, 22 (37\%) were in 8th month of gestation, 21 (35\%) in 9th and 21 (28\%) were in 7 th month of gestation. In relation to occupation, majority, i.e. 59 (98.3\%) of them, were house wives. In respect to years of married life, majority had married since 2 years. With regard to saving money, majority of them, i.e. 47 (78.3\%) had not saved the money for delivery. Majority of them did not have knowledge related to childbirth, i.e. $42(70 \%)$ and only $18(30 \%)$ have knowledge. Majority got the knowledge from family and relatives, i.e. 9 (50\%) and 7 (38.8\%) got the knowledge from books/magazines only $2(11.11 \%)$ got the knowledge from healthcare professionals.

The data represented in Table 1 compares the pretest and the post-test knowledge scores of the samples where in pretest majority of the samples $40(66.66 \%)$ have scored poor marks whereas in post-test only 2 samples scored poor marks. In pretest 19 (31.66\%) scored average marks but in post-test majority, i.e. $36(60 \%)$ scored average marks. In pretest, only single sample scored good marks but in post-test 22 (36.66\%) samples scored good marks. This shows the intervention done was effective.

The data represented in Table 2 show the mean of pretest is very less, i.e. 7.05 with SD 3.561016 as compared to post-test where mean is 15.2 with SD 3.590729. $\mathrm{t}$ calculated value, i.e. 5.096322, is greater than $\mathrm{t}$ table value, i.e. 2.238152. This difference was statistically significant at $p<0.01$ level with ' $t$ '-value of 5.096322 .

Hence, rejected $\mathrm{H} 0$ and accepted $\mathrm{H} 1$. It shows there is significant increase in knowledge after structured childbirth education program. Structured childbirth education program is found to be effective to increase primigravidae knowledge related to labor process. The researcher found that there is no association with any of the selected demographic variable, as the calculated Chi-square value is less than the table value, so accepted $\mathrm{H} 0$ and rejected $\mathrm{H} 1$, i.e. there is no association of demographic variables with knowledge score.

\section{DISCUSSION}

Analysis showed there is significant increase in knowledge after structured childbirth education program. Structured childbirth education program is found to be effective to increase primigravidae knowledge related to labor process. The researcher found that there is no association with any of the selected demographic variable, as the calculated Chi-square value is less than the table value.

Study has been supported with many different studies, which shows that mothers have less knowledge 
about childbirth process and structured childbirth education program is effective and helpful for mothers during delivery and relieves their stress and pain level. As a study, conducted on development and evaluation of a childbirth education program for Malawian women, where researcher found out association with important increases in maternal knowledge about antenatal, labor and birth and postnatal topics. ${ }^{5}$

A cohort study was conducted by Fabian HM and Radestad IJ to investigate first time mother's views about childbirth and parenthood education, in Sweden. The sample consisted of 1197 women, who completed three questionnaires during early pregnancy, 2 months and 1 year after giving birth. The study revealed that childbirth education helped $74 \%$ of first time mothers to prepare for childbirth and also recommends to conduct more research on current forms of antenatal education. ${ }^{6}$

\section{CONCLUSION}

The following conclusion was drawn from the study findings that there is significant increase in post-test knowledge score after intervention. Structured childbirth education program is found to be effective to increase primigravidae knowledge related to childbirth and preparing them for childbirth.

\section{REFERENCES}

1. Hearren J. Social Process and Childbirth Education: an Oral History [Online]. Available at: URL: http:/ /www.instituteofmidwifery.org/MSFinalProj.nsf/a9ee58d7a 82396768525 684f0056be8d/2d251634874296ee85256b0 d004be38d?Open Document.

2. Phlips CR. A basic text, family centered maternity/newborn care. 3rd ed. Mosby year book. p. 167-176.

3. The Bradley Method of Natural Childbirth. Childbirth Goals [Online]. Available at: URL: www.bradleybirth.com/tbm2. htm8/10/01.

4. Child birth education classes [Online]. Available at: URL: www.india parenting.com/pregnancy/data/preg 47 04.shtml. 14K.26/08/2007.

5. Malata, Chirwa E. Assessment of the effectiveness of childbirth education in Malawi. African Journal of Midwifery and Women's Health 2011 Apr;5(2):67-72 [Online]. Available at: URL: https:/ / www.intermid.co.uk/cgi.

6. Fabian HM, Radestad IJ. Childbirth and parenthood education classes in Sweden women's opinion and possible outcomes. J Obstet Gynecol Neonatal Nurs 2005;84(5):436-443. 